\title{
The effect of bromhexine, gentamicin and imipenem on biofilm of standard bacterial Escherichia coli and Pseudomonas aeruginosa by ELISA method
}

\author{
Mohamad Hamzeie ${ }^{1}$, Bizhan Nomanpour ${ }^{2}$, Abbas Akhavansepahy ${ }^{3}$ \\ ${ }^{I}$ MSc in Microbiology, Department of Microbiology, Faculty of Life Sciences, Islamic Azad University-Tehran North of \\ Branch, Tehran, Iran \\ ${ }^{2}$ Assistant Professor, Department of Microbiology, Faculty of Medicine, Kermanshah University of Medical Sciences, \\ Kermanshah, Iran \\ ${ }^{3}$ Associate Professor, Department of Microbiology, Faculty of Life Sciences, Islamic Azad University-Tehran North of \\ Branch, Tehran, Iran
}

\begin{abstract}
Background: Biofilms are a collection of microorganisms that have the ability to stick to different levels. Due to the difficulty of treatment of bacterial biofilm infections and their lack of recognition by conventional diagnostic methods, this study aimed to provide a new method of identification and the effect of related drugs on Pseudomonas aeruginosa and Escherichia coli biofilms.

Materials and methods: In this study, two strains of Escherichia coli and Pseudomonas aeruginosa were used. Using the microplate method, gentamicin and imipenem combined with bromhexine and also bromhexine alone with different dilutions were used on the biofilm of these bacteria. Then results read out using ELISA reader.

Results: Bromhexine alone and without combining with other substances or types of antibiotics had a positive effect on preventing the formation of biofilms and bacterial adhesion, and reduced Pseudomonas aeruginosa and Escherichia coli in the biofilm.

Conclusion: Biofilm has been able to grow significantly, despite the use of strong antibiotics such as imipenem and gentamicin. Its existence in the body, or devices such as urethral catheters, cardiac artificial valves or other artificial organs, causes a significant disorder within immune system.
\end{abstract}

Keywords: Biofilm, Escherichia coli, Pseudomonas aeruginosa, Bromhexine, ELISA.

Cited as: Hamzeie M, Nomanpour B, Akhavansepahy A. The effect of bromhexine, gentamicin and imipenem on biofilm of standard bacterial Escherichia coli and Pseudomonas aeruginosa by ELISA method. Medical Science Journal of Islamic Azad University, Tehran Medical Branch 2019; 29(3): 216-221.

Correspondence to: Bizhan Nomanpour

Tel: +9120413083

E-mail: bijann1397@yahoo.com

ORCID ID: 0000000288135959

Received: 20 Nov 2018; Accepted: 5 Dec 2018 
مجله علوم يزشكى دانشگاه آزاد اسلامى

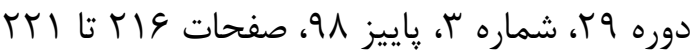

Original

Article

\title{
بررسى تأثير داروهاى برم هكَزين، جنتامايسين و ايمى ينهم روى بيوفيلهم \\ باكتريايى استاندارد اشرشيا كلاى و سودوموناس آئروزينوزا به روش الايزا
}

\author{
محمد حمزئى'، بيثزن نعمان بيور'، عباس اخوان سيهـى
}

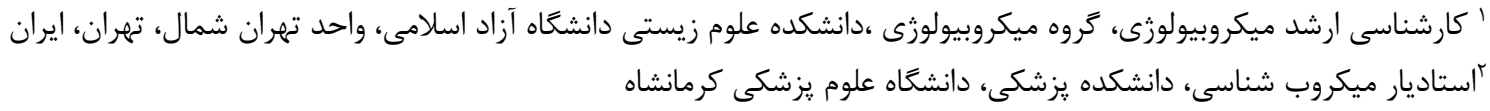

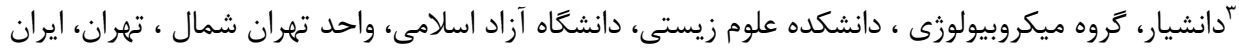

جكيده

سابقه و هدف: : بيو فيلمها اجتماعى /ز ميكرواركانيسه هستند كه توانايى جسبيدن به سطوح مختلف را دارند. با توجه به مشكل بودن

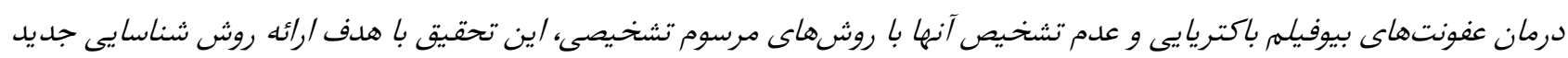

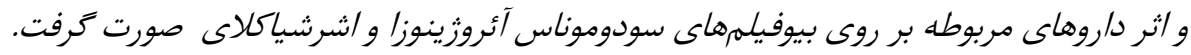

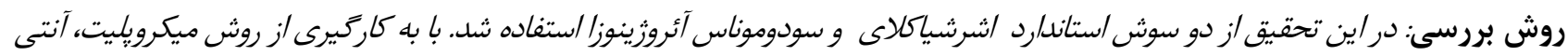

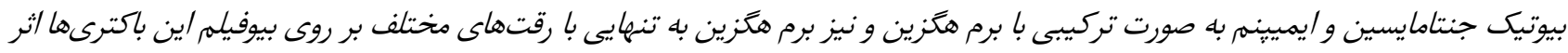

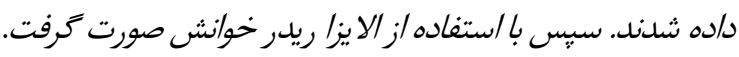

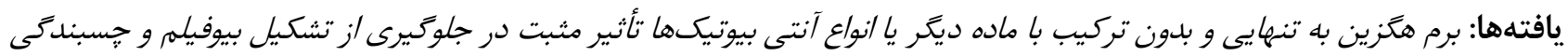

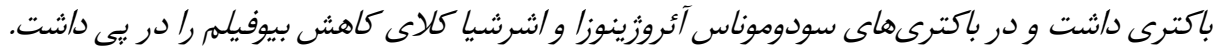

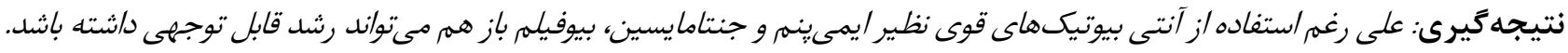

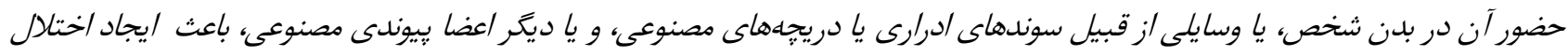

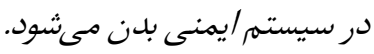
وازثان كليدى: بيوفيلم، /شرشياكلاى، سودوموناس آئروزينوزا، برم هكزين، الايزا.

ايجاد عفونت در بيمارستانها است. عامل انواع مختلفى از مقله

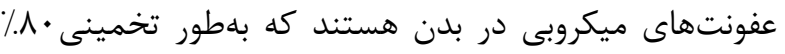
اين عفونتها را شامل مىشوند. از جمله عفونتهاى بله وجود

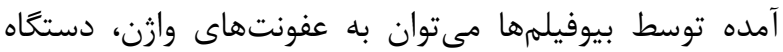

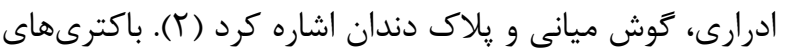

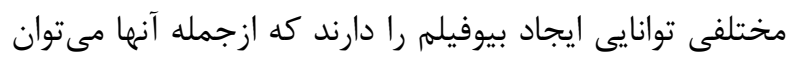
به سودوموناس آئروزينوزا، اشرشياكلاى، ليستريا مونوسيتوزئز استافيلوكوكها و با سيلوسها اشاره كرد ( إ, T).

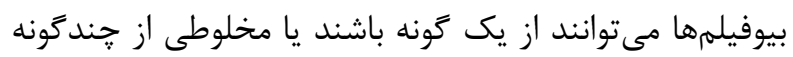
كه در سال 19V1 توسط كاسترتون در مورد باكترىها شرح آدرس نويسنده مسئول: كرمانشاه، دانشگاه علوم يزشكى كرمانشاه ، بيرّن نعمان يور (email: bijann1397@yahoo.com) ORCID ID: 0000000288135959 داده شدند (ץ). در شرايط استرس سبب جسبيدن باكترىها بيوفيلمها جمعيت ميكروبى متراكمى هستند كه به سطوح

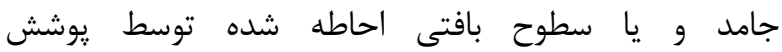

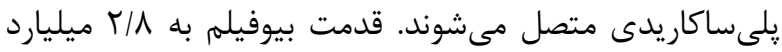

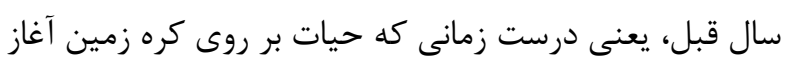

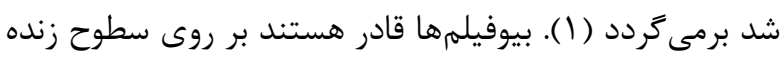

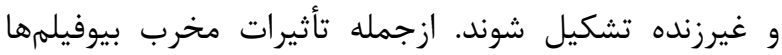

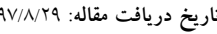
تاريخ بذيرش مقاله: 9V/9/I4 


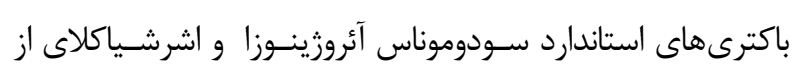

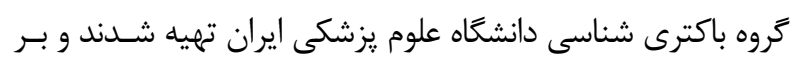

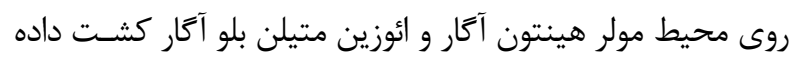

شند.

\section{توليد بيوفيلم با استفاده از روش ميكرويليت}

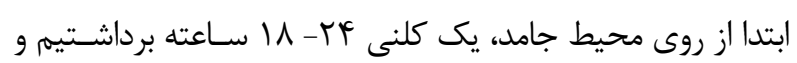

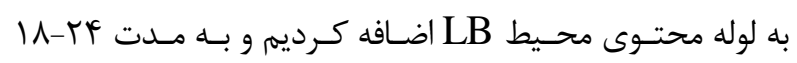

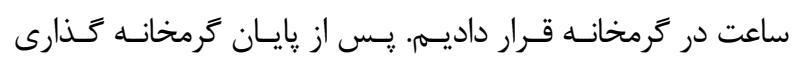

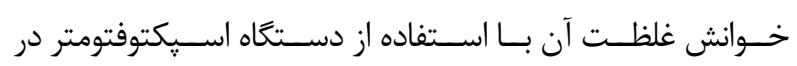

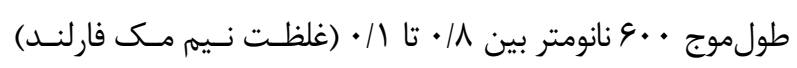

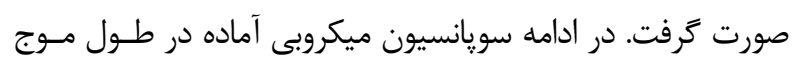

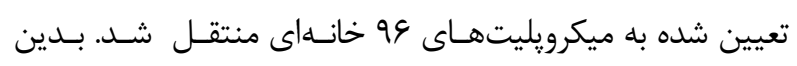

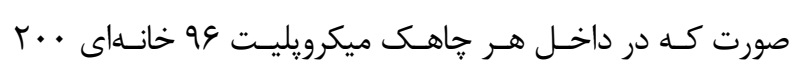

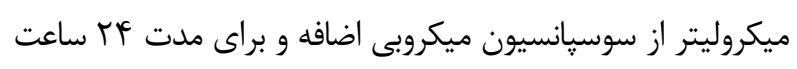

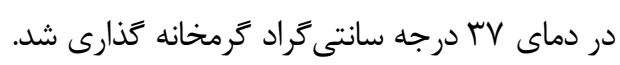

\section{سنجش توليد بيوفيلم}

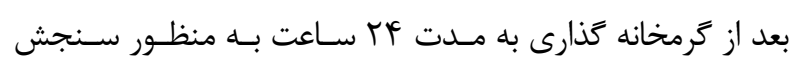

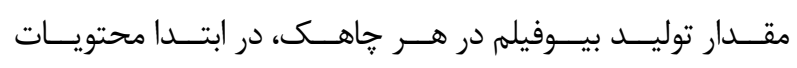

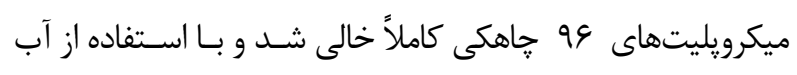

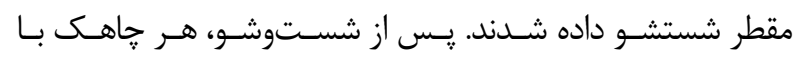

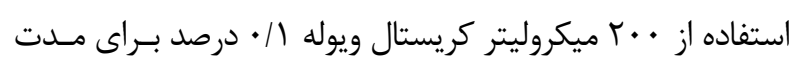

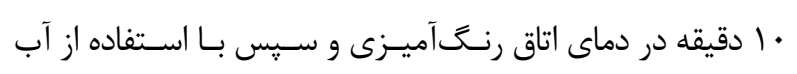

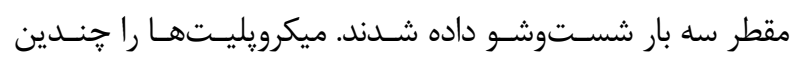

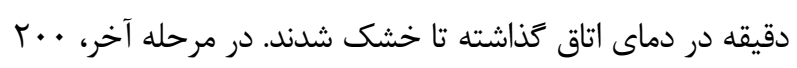

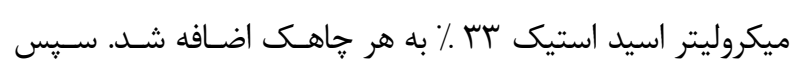

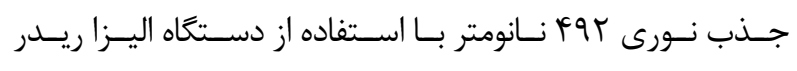

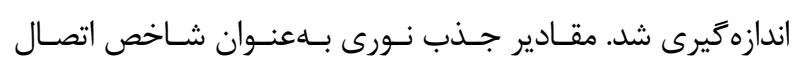

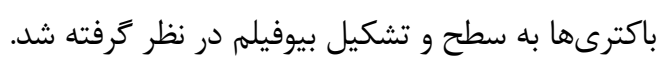

\section{آزمون تعيين MIC}

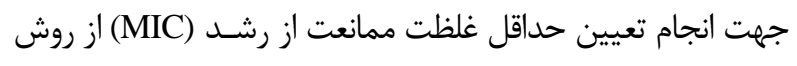

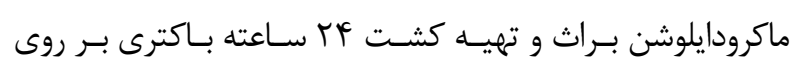

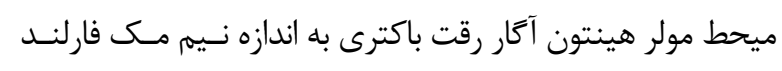
اس cfu

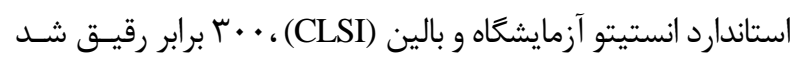

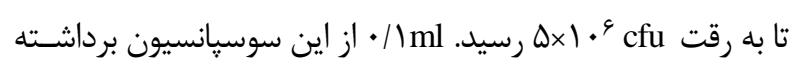

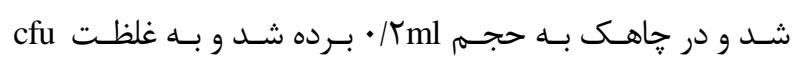

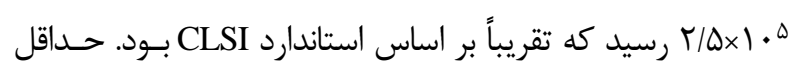

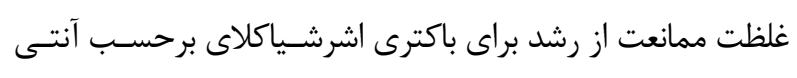

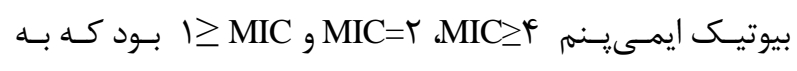

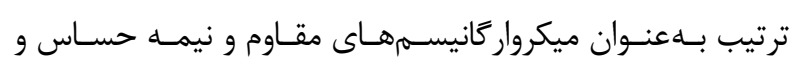

به سطوح مختلف مىشوند و اصولاً باكترىها با تشكيل بيوفيلم

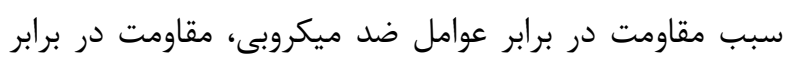

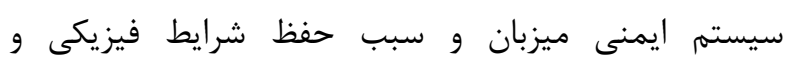

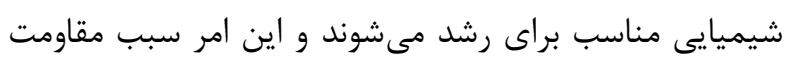

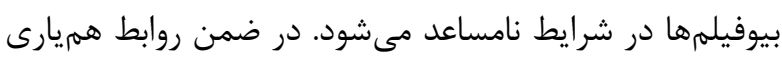

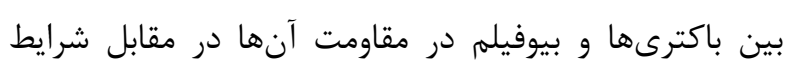

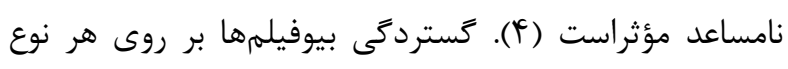

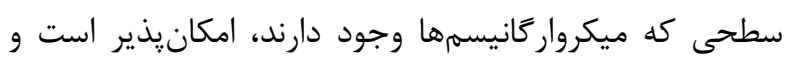

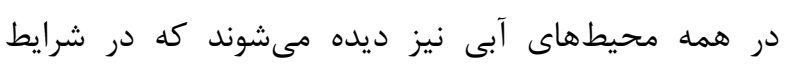

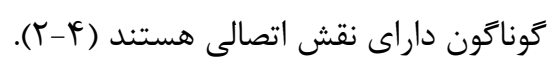

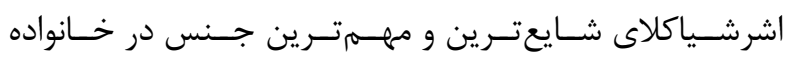

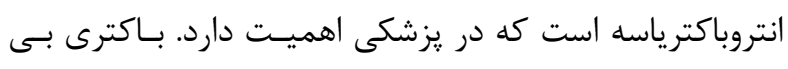

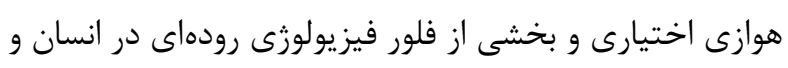

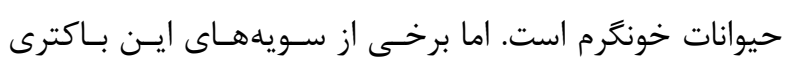

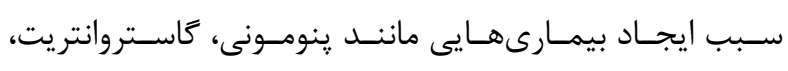

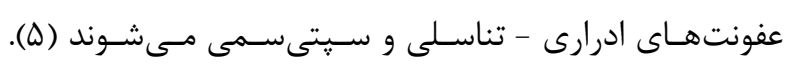

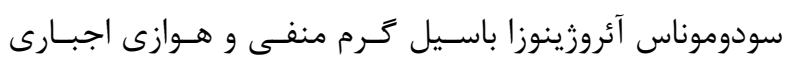

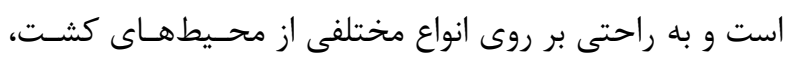

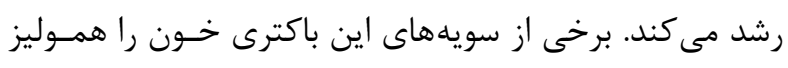

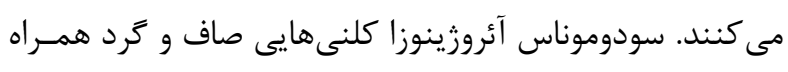

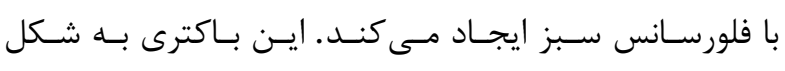

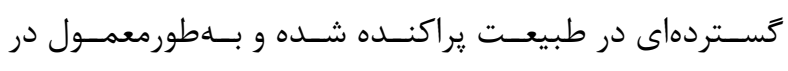

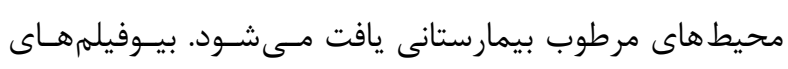

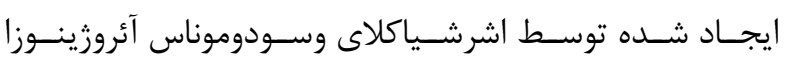

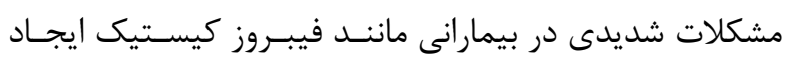

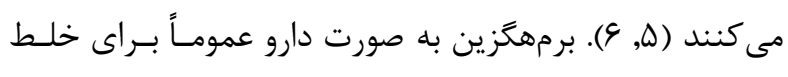

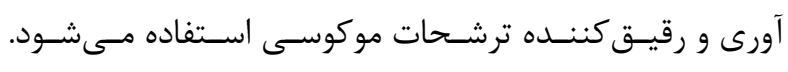

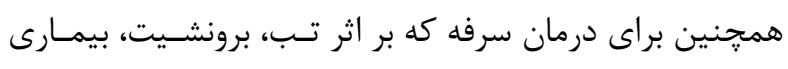

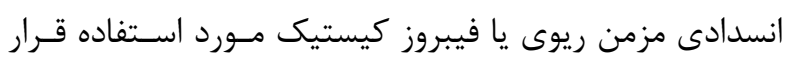

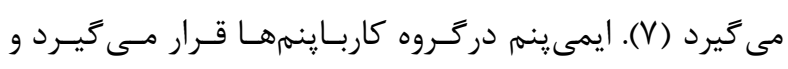

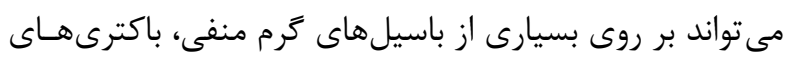

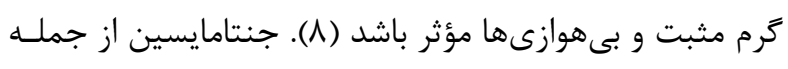

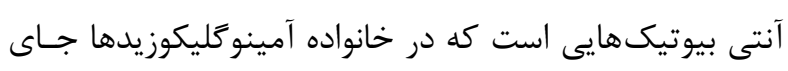

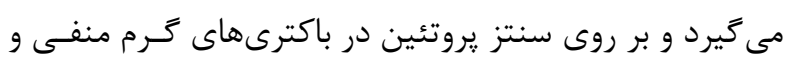

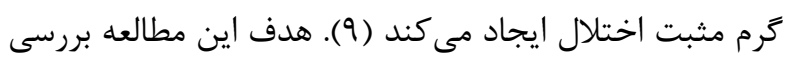

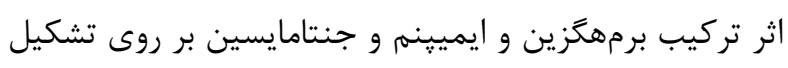

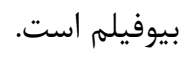

مواد و روشها جمع آورى سويههاى استاندارد باكتريايى روشيا 
بودند (جدول (). در باكترى سودوموناس آئروزينوزا ميانكين

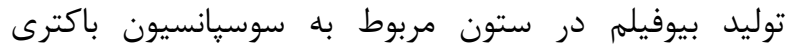
سيت

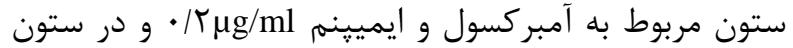

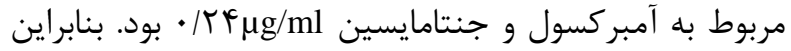

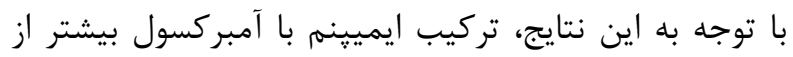

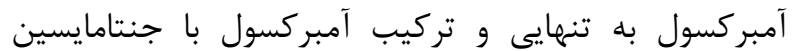
برروى پايين آوردن بيوفيلم تاثير داشتند. بالاترين غلظت آمبركسول T/VD ميكروكرم در هر ميلى ليتر و بالاترين غلظت

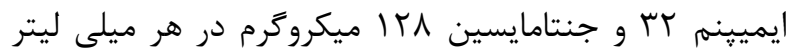
بود و هر كدام تا I ا رقت يايينتر هم موثر بودند (جدول ك).

\section{بحث}

اهميت بيوفيلمها در جوامع امروزى به حدى است كه در حوزه يزشكى و تجهيزات مربوطه و همجنين در صنعت مواد غذايى

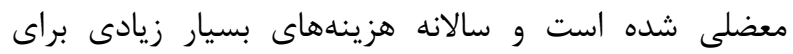
يروهش در زمينه از بين بردن و جلوكيرى از تشكيل بيوفيلمها

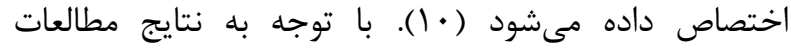

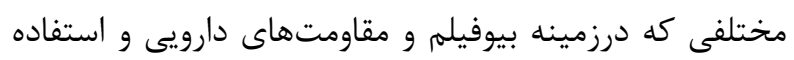
از انواع عصارهها انجام شده است، مشاهده شده است كه

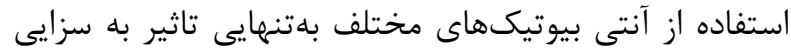

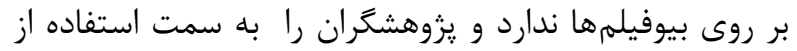

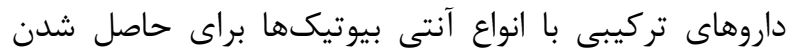
نتيجه بهتر در درمان اين ساختارهاى مقاوم سوق مى بدهد
حساس تلقى شد و برحسب آنتى بيوتيـك جنتامايسـين مقـدار

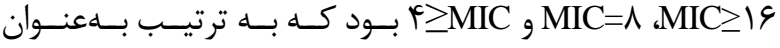

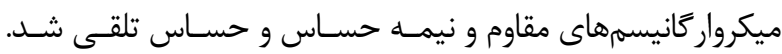

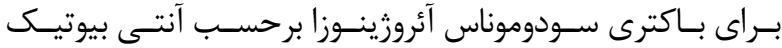
ايميينهم مقدار MIC MIC و MIC و

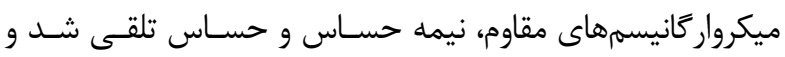
برحسب آنتى بيوتيك جنتامايسـين MIC و MIC=19 ، MIC

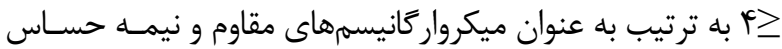
و حساس تلقى شد.

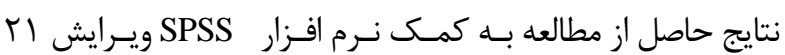
مورد تحليل آمارى قرار كرفت.

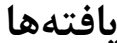

در باكترى اشرشياكلاى ميانخين توليد بيوفيلم در رديف

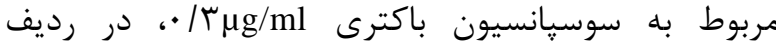

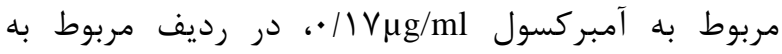
آمبر كسول و ايميينم

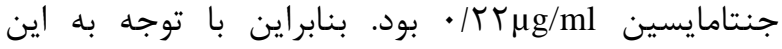

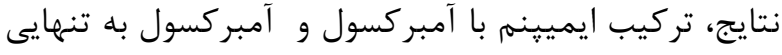

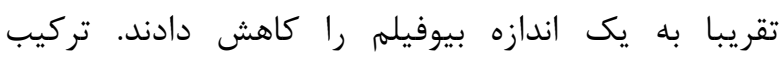
آمبركسول با جنتامايسين بر روى يايين آوردن بيوفيلم نسبت به خود آمبركسول تاثير جندانى نداشت. بالاترين

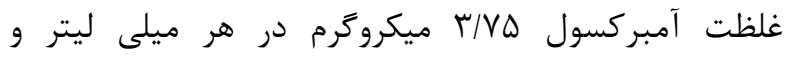

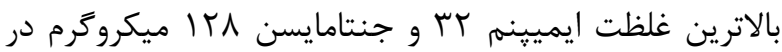
هر ميلى ليتر بود و هر كدام تا Iا رقت پإيينتر هم موثر

جدول ا. دادهاى اندازه گيرى شده توسط الايزا در رقتهاى مختلف در باكترى اشرشيا كلاى

\begin{tabular}{|c|c|c|c|c|c|c|c|c|c|c|c|c|}
\hline it & 11 & 1 . & 9 & $\Lambda$ & $\checkmark$ & 4 & $\Delta$ & f & r & r & 1 & \\
\hline q q & $\cdot / T V T$ & $\cdot / T \Delta F$ & . / RAK & Trז/ & $\cdot / \pi \Delta \Delta$ & $\cdot / \mu \Lambda$ & $\cdot \mid T Y I$ & $\cdot \mid r \Delta S$ & $\cdot \mid \pi 11$ & . & ו וז/ן. & سوسيانسيون باكترى \\
\hline . KRr & - RAT & . ITFE & $\cdot / / \Lambda \mathrm{V}$ & . /KG & $\cdot / 1 \Delta \Delta$ &.$/ 1 r \Delta$ & rr|/. & r & ه & rזו/. & $\cdot / T I F$ & آمبر كسول \\
\hline$\cdot / T V R$ & $\cdot / r \Delta \Lambda$ & $\cdot / T F$ & $\cdot / T F V$ & $\cdot / T \Delta S$ & $\cdot / r \mid 1$ & $\cdot / I r v$ & $\cdot / l f$ & (1/R & .1 .9 & $\cdot / \cdot \wedge \Delta$ & . & ايميينهم+آمبر كسول \\
\hline$\cdot / r q \Lambda$ & • & $\cdot|r F|$ &.$/ 1 \mathrm{~V}$ & $\cdot / T T I$ & $\cdot / 1 \wedge \vee$ & . & . /Irv & $\cdot / T \Delta H$ & . Tra & .1190 & $\cdot / t \cdot r$ & جنتامايسين +آمبر كسول \\
\hline
\end{tabular}

جدول r. دادههاى اندازه گيرى شده توسط الايزا در رقتهاى مختلف در باكترى سودوموناس آئروزينوزا

\begin{tabular}{|c|c|c|c|c|c|c|c|c|c|c|c|c|}
\hline it & 11 & 1. & 9 & $\Lambda$ & $\checkmark$ & 4 & $\Delta$ & f & r & r & 1 & \\
\hline$\cdot / V I T$ &.$|\Delta T|$ & $\cdot / D T$ & • & $\cdot / 4 q$ & $\cdot / 4$ & $\cdot / r V \Delta$ & . $/ F \Delta r$ & $\cdot / K \& V$ & $\cdot / \pi \cdot 4$ & ( & . /MFE & سوسيانسيون باكترى \\
\hline$\cdot|4|$ & . MFV & $\cdot / T \wedge F$ & $\cdot / 4$ & 面 & טזr/. & $\cdot / 4 q 4$ & $\cdot / T$ & 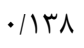 & $\cdot / r \cdot 9$ & - ITYK & $\cdot / r+q$ & آمبر كسول \\
\hline$\cdot / H \wedge F$ & $\cdot \mid \pi 11$ & $\cdot / T \Delta R$ & $\cdot / 4 \cdot 9$ & . /TFV & $\cdot / 4 \cdot 9$ & - MFT &.$/ 1 \mathrm{r} \Lambda$ &.$/ 1 T V$ & $\cdot 1 \cdot \vee 9$ & .1 .94 & .1114 & ايميينم++آمبر كسول \\
\hline$\cdot$ / KVG & $\cdot /$ RV & . RTD & . & . & $\cdot / 1 \wedge \Delta$ & $\cdot / \pi / 1$ & .1194 & . TSK & $\cdot / r T q$ &.$/ N \mu F$ & $\cdot r \cdot r$ & جنتامايسين +آمبر كسول \\
\hline
\end{tabular}




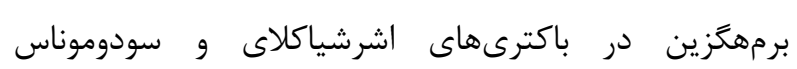

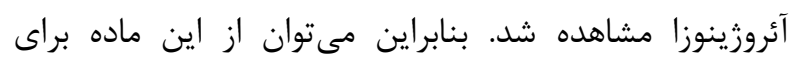

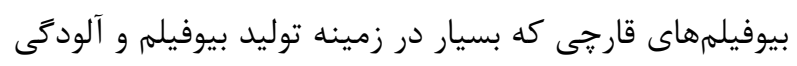

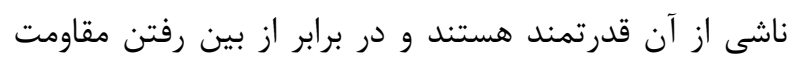

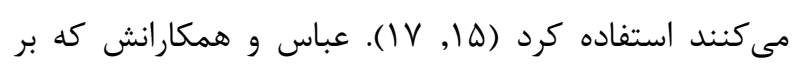

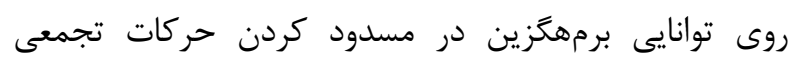

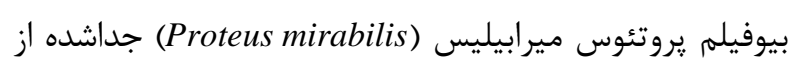

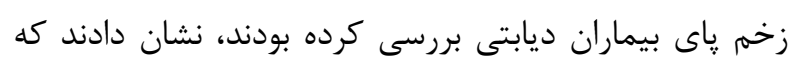

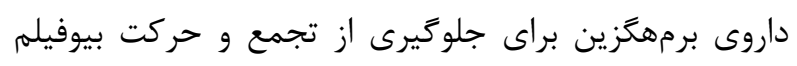

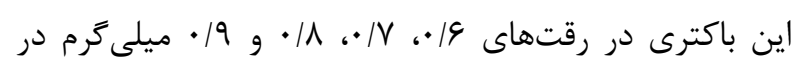

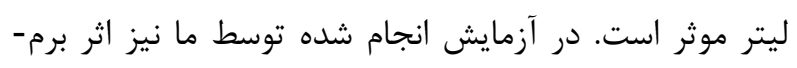

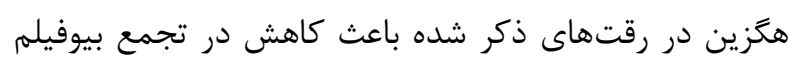

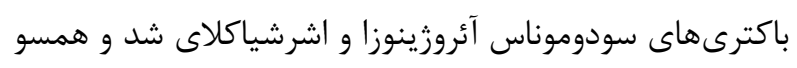

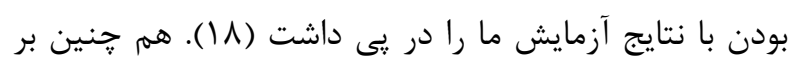

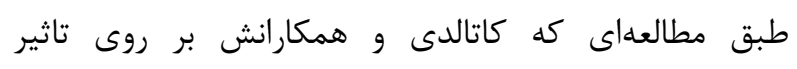

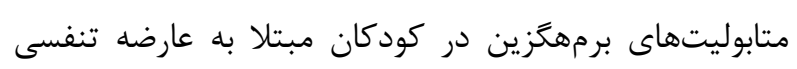

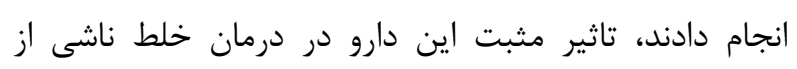

عفونت تنفسى مشاهده شد (9 (1).

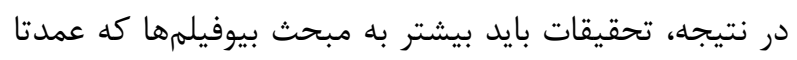

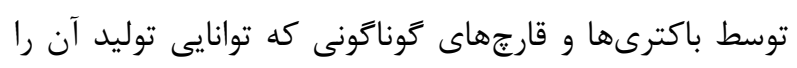

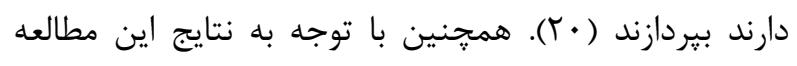

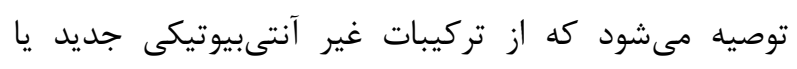
تركيب داروهاى ضد بيوفيلم مانند برمهكَزين با آنتى بيوتيكها تئيا

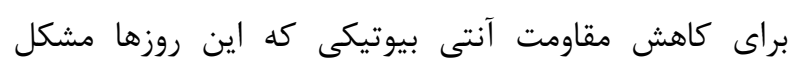

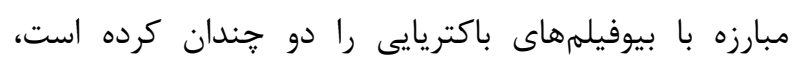

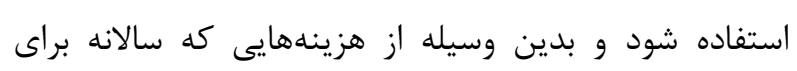

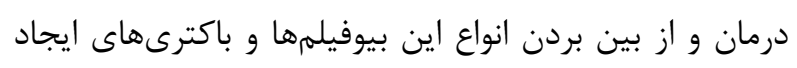

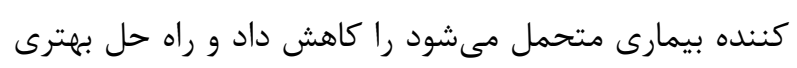
را براى بيماران جهت درمان ترسيم كرد.

\section{تشكر و قدردانى}

اين مقاله نتيجه طرح يزوهشى محمد حمزئى دانشجوى

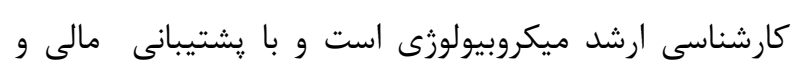
ادارى معاونت محترم تحقيقات و فناورى دانشكاه آزاد اسلامى إنى

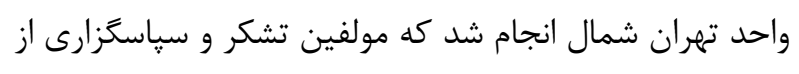

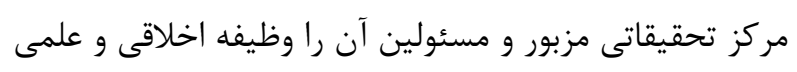
خود مى دمانند.

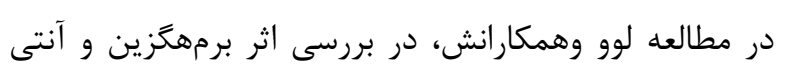

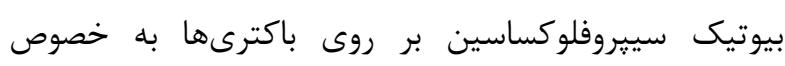

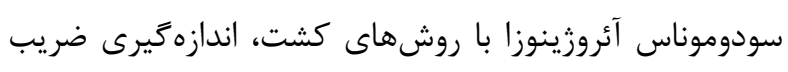

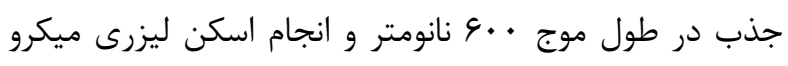

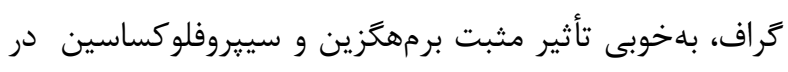

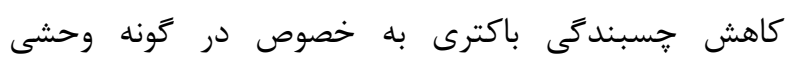

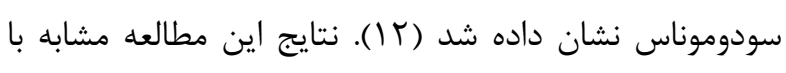

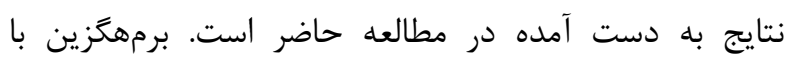

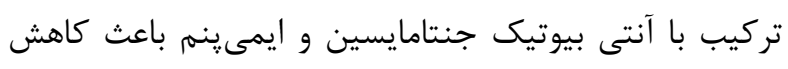

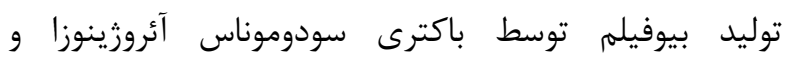

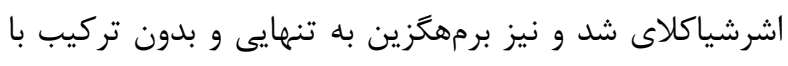

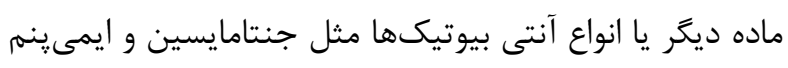

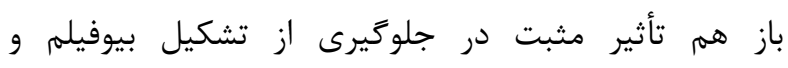
جسبندكى باكترىها داشت.

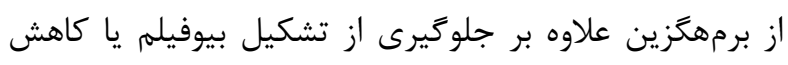

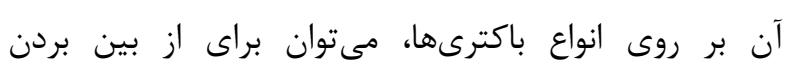

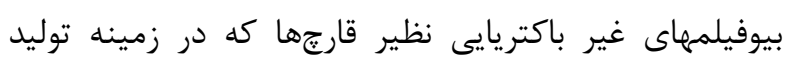

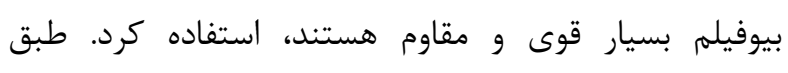

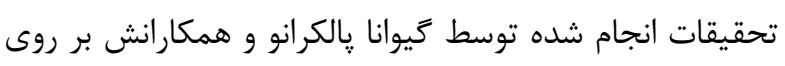

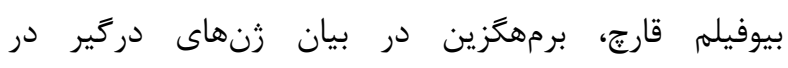

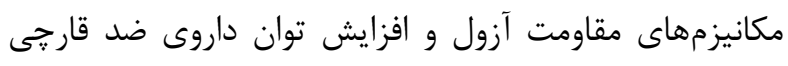

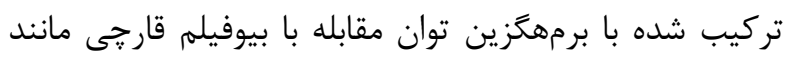

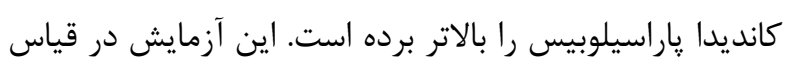

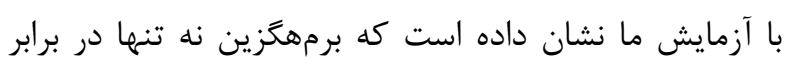

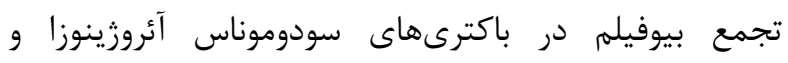

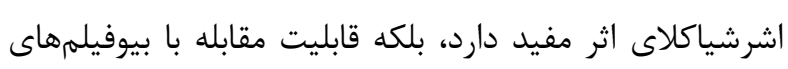

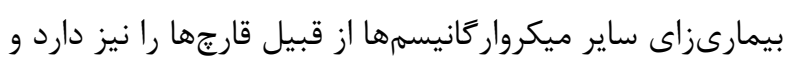

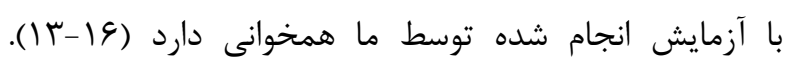

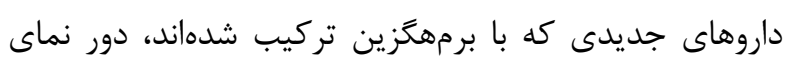

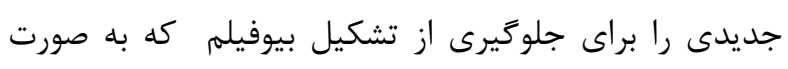

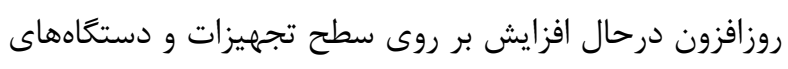

$$
\text { يزشكى است را نشان مى دهد. }
$$

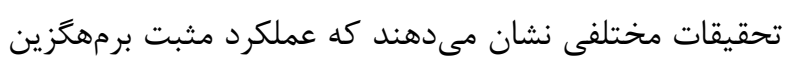

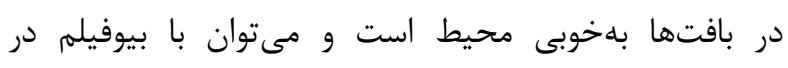

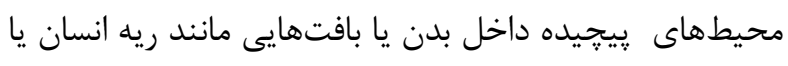

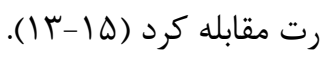

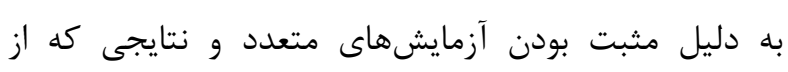

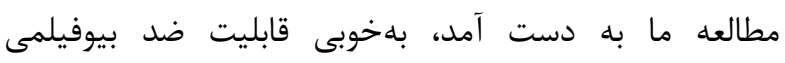

\section{REFERENCES}

1. Moser C, Pedersen HT, Lerche CJ, Kolpen M, Line L, Thomsen K, et al. Biofilms and host response-helpful or harmful. APMIS 2017;125:320-38. 
2. Abedon ST. Ecology of anti-biofilm agents II: bacteriophage exploitation and biocontrol of biofilm bacteria. Pharmaceuticals 2015;8:559-89.

3. Ghannoum M, O'Toole GA, Eds. Microbial biofilms. New York: ASM Press; 2004.

4. López D, Vlamakis H, Kolter R. Biofilms. Cold Spring Harb Perspect Biol 2010;2:a000398.

5. Brooks GF, Carroll KC, Butel JS, Morse SA, Mietzner TA, Eds. Jawetz, Melnick and Adelberg's medical microbiology. 25th edition. Philadelphia: McGraw-Hill Companies; 2006.

6. Pawar V, Komor U, Kasnitz N, Bielecki P, Pils MC, Gocht B, et al. In Vivo Efficacy of Antimicrobials against Biofilm-Producing Pseudomonas aeruginosa. Antimicrob Agents Chemother 2015;59:4974-81.

7. Hall-Stoodley L, Costerton JW, Stoodley P. Bacterial biofilms: from the natural environment to infectious diseases. Nat Rev Microb 2004;2:95-108.

8. Kropp H, Gerckens L, Sundelof JG, Kahan FM. Antibacterial activity of imipenem: the first thienamycin antibiotic. Rev Infect Dis 1985;7:S389-S410.

9. Chen C, Chen Y, Wu P, Chen B. Update on new medicinal applications of gentamicin: evidence-based review. J Formos Med Assoc 2014;113:72-82.

10. Hall CW, Mah T-F. Molecular mechanisms of biofilm-based antibiotic resistance and tolerance in pathogenic bacteria. FEMS Microbiol Rev 2017;41:276-301.

11. Trancassini M, Iebba V, Citerà N, Tuccio V, Magni A, Varesi P, et al. Outbreak of Achromobacter xylosoxidans in an Italian Cystic fibrosis center: genome variability, biofilm production, antibiotic resistance, and motility in isolated strains. Front Microbiol 2014;5:138.

12. Lu Q, Yu J, Yang X, Wang J, Wang L, Lin Y, et al. Ambroxol interferes with Pseudomonas aeruginosa quorum sensing. Int J Antimicrob Agents 2010;36:211-5.

13. Azeredo J, Azevedo NF, Briandet R, Cerca N, Coenye T, Costa AR, et al. Critical review on biofilm methods. Crit Rev Microbiol 2017;43:313-51.

14. Borghi E, Borgo F, Morace G. Fungal Biofilms: Update on Resistance. Adv Exp Med Biol 2016;931:37-47.

15. Syed M, Chopra R, Shrivastava V, Sachdev V. Comparative evaluation of $0.2 \%$ Chlorhexidine Mouthwash, Xylitol Chewing Gum, and Combination of 0.2\% Chlorhexidine Mouthwash and Xylitol Chewing Gum on Salivary Streptococcus mutans and Biofilm Levels in 8- to 12-Year-Old Children. Int J Clin Pediatr Dent 2016;9:313-319.

16. Pulcrano G, Panellis D, De Domenico G, Rossano F, Catania MR. Ambroxol influences voriconazole resistance of Candida parapsilosis biofilm. FEMS Yeast Res 2012;12:430-8.

17. Junior JCEM. Effectiveness of oral antiseptics on tooth biofilm: a study in vivo. J Contemp Dent Pract 2015;16:6748.

18. Abbas HA. Ambroxol blocks swarming and swimming motilities and inhibits biofilm formation by Proteus mirabilis isolated from diabetic foot infection. Asian J Pharm Technol 2013;3:109-16.

19. Cataldi M, Sblendorio V, Leo A, Piazza O. Biofilm-dependent airway infections: a role for ambroxol? Pulm Pharmacol Ther 2014;28:98-108.

20. Nett JE, R Andes D. Fungal biofilms: In vivo models for discovery of anti-biofilm drugs. Microbiol Spectr 2015;3:E30. 